\title{
Heterogeneity of the Blood Pressure Distribution Among Solomon Islands Societies With Increasing Acculturation
}

\author{
KIM E. ZERBA, JONATHAN S. FRIEDLAENDER, AND \\ CHARLES F. SING \\ Department of Human Genetics, University of Michigan, Ann Arbor, \\ Michigan 48109 (K.E.Z., C.F.S.); Department of Anthropology, Temple \\ University, Philadelphia, Pennsylvania 19122 (J.S.F.)
}

KEY WORDS Anthropometric survey, Genetic differences, Geneenvironment interactions

ABSTRACT This study illustrates the very complex nature of gene by
environmental interactions influencing the blood pressure (BP) distribution in
a series of genetically distinctive populations undergoing rapid acculturation.
We report the results of two BP and anthropometric surveys on Solomon
Islands societies separated by an interval of 14 to 19 years. While differences in
acculturation existed at the time of the initial survey, the interval between
surveys was marked by rapid acculturation in almost all societies. Seven of the
eight societies originally covered were included in the resurvey, and a large but
variable proportion of the original sample subjects was recovered in the
follow-up.

Because the genetic relationships of the societies have been described, we were able to establish the following points concerning the role of genetic differences in determining the distribution of $\mathrm{BP}$ among these populations and, more important, the interaction of these genetic differences with changes associated with increasing acculturation: 1) In the initial survey, mean adjusted systolic and diastolic BPs were significantly heterogeneous among societies within and among genetically related clusters of societies (genetic clusters) and sexes. At the same time, rank differences in these means were not associated with rank differences in acculturation status among societies ignoring cluster membership. 2) Importantly, in the follow-up survey increasing acculturation resulted in the disappearance of significant differences in mean systolic and diastolic BP among genetic clusters in males, despite continued significant heterogeneity among societies within genetic clusters. In females, differences among genetic clusters persisted, but the degree of significance was substantially less with increasing acculturation. We interpret these changes as evidence for genotype by environment interaction. 3) There were significant differences in interindividual variances of both systolic and diastolic BPs among genetic clusters in the first survey. Ranks of these variances were not significantly associated with acculturation rank. In the follow-up survey, however, most societies showed striking increases in the variance of both systolic and diastolic BPs with increased acculturation. These increases in variance of both systolic and diastolic BPs may be related to a) shifts in demography and/or anthropometry of some societies; b) increased range and intensity of environmental factors affecting $\mathrm{BP}$ and associated with increased acculturation; and/or c) genotype by environmental interactions. 4) The correlation between systolic and diastolic BP decreased over the interval for all societies within and among genetic clusters. This trend was partly the result of larger changes in variances for systolic than diastolic BP in the resurveys. This study illustrates the enormous heterogeneity in the BP distribution that can occur even among populations with relatively similar ethnic and cultural backgrounds. 
Elevated blood pressure (BP) is a risk factor for cardiac, cerebrovascular, and peripheral vascular diseases. Both genetic and environmental factors are involved in determination of interindividual variation in $\mathrm{BP}$ within populations. Among populations, most interest has focused on environmental differences as an explanation for different incidence rates of essential hypertension (EH), defined as systolic BP greater than 140 $\mathrm{mm} \mathrm{Hg}$ or diastolic BP greater than $90 \mathrm{~mm}$ $\mathrm{Hg}$. For example, cardiovascular disease is cosmopolitan in distribution, but in studies of traditional societies with little Western influence and urbanization it is uncommon (Thomas, 1927; Donnison, 1929; Morse and Beh, 1937; Murrill, 1949; Whyte, 1958; Abbie and Schroder, 1960; Lowenstein, 1961; Maddocks, 1961; Mann et al., 1962, 1964; Hoobler, 1965; Shaper et al., 1969; BurnsCox and Maclean, 1970; Glanville and Geerdink, 1972; Truswell, 1972; Page et al., 1974; Prior et al., 1974; Oliver et al., 1975; Ward, 1983). Traditional societies subjected to increasing acculturation by migration to more accultured areas (Cruz-Coke et al., 1964; Prior et al., 1968; Marmot and Syme, 1976; Hanna and Baker, 1979; Ward et al., 1979; McGarvey et al., 1980; James et al., 1983; Poulter et al., 1985) or in situ changes in acculturation (Cruz-Coke et al., 1973; LaBarthe, 1973; Page, 1976, 1980; Cruz-Coke, 1987; Friedlaender and Page, 1987) often show an increase in BP, lipid levels, and incidence of cardiovascular disease. Crosssectional studies comparing island migrants versus nonmigrants (e.g., McGarvey and Baker, 1979; Ward, 1983) and studies of in situ acculturation (e.g., LaBarthe, 1973; McGarvey and Schendel, 1986) suggest that sociocultural changes rather than genetic factors are primarily responsible in the observed changes in BP during the process of acculturation. Almost nothing is known, however, about the interaction of genetic differences among populations with acculturation in the determination of interpopulation differences in $\mathrm{BP}$ distribution.

Our study addressed the association between initial genetic and acculturation differences among seven societies in the Solomon Islands and properties of the frequency distributions of systolic and diastolic $\mathrm{BPs}$, and the changes in these associations during the process of rapid in situ acculturation over a period of 14-19 years. We present evidence for enormous heterogeneity of the distributions of systolic and diastolic BPs among the Solomon Islands societies. The exact causes of this great heterogeneity remain unknown, but initial survey differences in BP distributions were associated with genetic strata rather than with initial differences in degree of acculturation. However, as these societies became rapidly acculturated over the 14-19 year interval, the BP distributions changed. With increasing acculturation, some of this heterogeneity is most likely related to 1 ) shifts in demography and/or anthropometry of some societies; 2) increased numbers of environmental factors associated with increased acculturation; and 3) gene by environment interactions. We will suggest that without measuring both genotypes and specific individual environmental exposures, comparisons among populations of multifactorial traits such as BP are likely to be very complex and difficult.

\section{MATERIALS AND METHODS Samples}

A comprehensive description of the survey design and samples is given by Friedlaender (1990). The Solomon Islands are located in the South Pacific, northeast of Australia and southeast of New Guinea. Maps of the study area are given by Page et al. (1974) and by Friedlaender (1990) in this issue. For this study, seven societies were intensively surveyed as part of the Harvard Solomon Islands Project by a team of anthropologists and physicians (Friedlaender et al., 1987). Six of the societies are Melanesian, including the non-Austronesian-speaking Nasioi, Nagovisi, and Aita from the island of Bougainville and the Austronesian-speaking Lau, Kwaio, and Baegu from the island of Malaita. The seventh society is PolynesianMicronesian, living on the atoll Ontong Java. All seven societies were surveyed during the time period 1966-72, resurveyed in 1978-80, and six of the populations (excluding Kwaio) resurveyed in 1985-86. A presentation of the 1978-80 survey results is given elsewhere (Friedlaender and Page, 1987). In this report we used the more complete data from the 1966-72 and 1985-86 surveys. We refer to the 1966-72 surveys as survey 1 and the 1985-86 surveys as survey 3 .

For the first survey, 1,822 persons were sampled ( 859 males and 963 females). For the third survey, 1,427 persons were sampled ( 620 males and 807 females). The first survey team attempted complete sampling of defined villages and hamlets within a specific region. In Baegu and Aita these 
strictly defined samples were enlarged with nonsystematic inclusion of individuals from adjacent areas. The follow-up survey (survey 3 ) included as many of the first survey subjects as possible and augmented the samples with children, spouses, and first degree relatives of survey subjects who were not part of the first survey. However, in Ontong Java, because of the exceptionally high recovery rates and a lack of time, almost no children were added in the resurvey. Recovery rates as percentages of individuals in survey 1 included in the follow-up 14-19 years later were overall, $38.6 \%$; Nasioi, $53.5 \%$; Nagovisi, $54.1 \%$; Aita, 28.8\%; Lau, 25.7\%; Baegu, $34.1 \%$; and Ontong Java, $63.1 \%$.

We tested for selection bias of individuals resampled in survey 3 by comparing, for each society and sex separately, the means ( $t$ test) and variances (Hartley test, approximate because of unequal sample sizes) of systolic and diastolic BPs for the subsamples of individuals in survey 1 who were and were not subsequently resurveyed. We found no significant differences in mean levels, but there were significant differences in variances in 7 of the 28 comparisons. These were not systematic in direction, although variances were more often smaller in the resurveyed subsamples. This may be a consequence of smaller sample sizes in these groups, which have not included the entire range of effects that influence BP.

\section{Blood pressure measurements}

$\mathrm{BP}$ was recorded by L.B. Page in the first survey (1966-72) and by J.S. Friedlaender in the third survey (1985-86). BP was obtained from the right arm with the subject seated comfortably. Systolic and diastolic (Korotkoff phases I, IV, and V) BPs were recorded, but only phases I and IV measurements were used in these analyses. Anthropometrics were taken by Friedlaender in survey 3 and by three different observers in survey 1 . Inter- and intraobserver biases in anthropometric measurements were not formally treated, but all observers were trained by $\mathrm{A}$. Damon. Friedlaender and Page overlapped in the second surveys in 1978-80, and analysis of variance indicated no systematic or significant differences in their BP measurement techniques (Friedlaender and Page, 1987).

\section{Genetic clusters}

Overall, genetic differences among societies were reflected in separation of societies geographically by islands and atoll into three distinct clusters (hereafter called genetic clusters) of Bougainville, Malaita, and Ontong Java (Table 1), and are discussed in detail by Friedlaender (1990). Briefly, genetic differences were determined in the first survey from a complex set of multivariate relationships among 1) blood groups, red cell enzymes, and immunoglobin markers (Rhoads and Friedlaender et al., 1987), 2) dermatoglyphics (Froehlich, 1987), and 3) odontometrics (Harris and Bailit, 1987). An overall similarity ranking was derived from these three data sets. Within the Bougainville cluster, the Nasioi and Nagovisi were more similar genetically, while the Aita were distinctly separate. Within the Malaita cluster, the Lau and Baegu were most similar, with Kwaio being distinctly separate. The Ontong Javanese, although different from the other two genetic clusters, showed more affinities with the Malaita group than with the Bougainville group.

\section{Acculturation}

Acculturation differences among these societies in duration and intensity of contact with industrialized societies with consequent alterations in diet, education, religion, medical care, demography, anthropometry, and basic economy were first described and systematically compared in detail by Page et al. (1974, except for Ontong Java) and subsequently by Friedlaender and Page (1987) and by Friedlaender (1990). Our analyses of

TABLE 1. Description of genetic clusters ${ }^{\dagger}$ and degree of acculturation ${ }^{2}$ among the Solomon Island societies

\begin{tabular}{llll}
\hline \multirow{2}{*}{$\begin{array}{lll}\text { Genetic } \\
\text { cluster }\end{array}$} & Society & \multicolumn{2}{c}{ Degree of acculturation } \\
\cline { 3 - 4 } Bougainville & Nasioi & +++ & ++++ \\
& Nagovisi & +++ & ++++ \\
& Aita & + & ++ \\
Malaita & Lau & ++ & +++ \\
& Baegu & + & ++ \\
& Kwaio & 0 & Not sampled \\
Ontong Java & Ontong Java & + & +++ \\
\hline
\end{tabular}

${ }^{1}$ Genetic clusters were determined from a complex set of multivariate relationships among 1) blood groups, red cell enzymes, and immunoglobin markers; 2) detailed an thropometric measurements; 3) dermatogly phics; and 4) odontometrics and compared with linguistic and geographical relationship among societies and are dis cussed in detail by Friedlaender (1990).

"Degree of acculturation represents the following reduced to an ordinal scale $(0-++++)$ : acculturation differences among societic in duration and intensity of contact with industrialized societies with consequent alterations in diet, education, religion, medical care, and basic economy. These differences were first described in detail by Page et al. (1974, except (Ontong dava) and subsequently by Friedlaender and Page (1987) and Friedlaender (1990). 
the effects of acculturation on BP (see below) are based on their summary "degree of acculturation," a ranking of the acculturation differences reduced to an ordinal scale (Friedlaender et al., 1987; Friedlaender, 1990). During the initial set of surveys, the Nasioi, Nagovisi, and Lau were considerably more acculturated than the Aita, Baegu, Kwaio, and Ontong Javanese (Table 1). The Kwaio were the least acculturated of all the societies, although all were considered quite unacculturated by Western standards. By the last set of surveys nearly 20 years later all societies (except the Kwaio, who were not resurveyed because of political unrest in the region) had increased substantially in their degree of acculturation, with an accompanying decrease in acculturation differences among societies. This observed general increase in degree of acculturation over the interval was a primary focus of our analyses.

\section{Statistical design and analyses}

The three distinct genetic clusters of societies on Bougainville, Malaita, and Ontong Java (Friedlaender, 1990) provided a quasiexperimental nested design (sensu Ward, 1983) of societies within genetic clusters by which we could examine the effects of rapid in situ acculturation on individuals surveyed over a 14-19 year interval. Our analytic strategy was 1) to test for homogeneity in the contribution of age, weight, and height to the variation in systolic and diastolic BPs among societies and genetic clusters; 2) after appropriate adjustment for the effects of these biological concomitants, to examine the pattern of means of systolic and diastolic BPs among societies and genetic clusters; 3) to examine the homogeneity of variances of systolic and diastolic BPs across the same strata; 4) to examine the homogeneity of correlations of systolic and diastolic BPs across the same strata; and, finally, 5) to examine the differences in the results of these analyses between surveys 1 and 3. Genetic differences among societies were considered constant during this study because the time interval between surveys 1 and 3 was less than one generation and intersociety migration was negligible. Therefore, if we observed systematic differences in results of analyses from the first survey compared with the third, they could be at least partially attributed to environmental effects of acculturation and/or gene by environment interaction.

All analyses employed the Statistical Analysis System (SAS Institute, 1985).
When specialized techniques were unavailable with standard SAS procedures, they were programmed using SAS interactive matrix language (Proc IML). All analyses were performed separately by survey and sex. We set $\alpha$ levels for all tests of significance at 0.05 . Distributions were skewed and variances unequal among societies for many of the traits. Since all of the statistical tests we used are robust against even moderate departures of normality and heteroscedasticity and because we wanted the variables presented in commonly used scales, we chose not to use transformations.

We defined our nested analysis of variance (NANOVA; Neter et al., 1985) model as

$$
\mathrm{Y}_{\mathrm{ijk}}=\mu_{. .}+\alpha_{\mathrm{i}}+\beta_{\mathrm{j}(\mathrm{i})}+\epsilon_{\mathrm{k}(\mathrm{ij})},
$$

where $Y_{i j k}$ is the phenotype of the kth individual in the jth society and ith genetic cluster, $\mu$. is the grand mean, $\alpha_{i}$ is the effect of the ith genetic cluster, $\beta_{j(i)}$ is the effect of the jth society in the ith genetic cluster, and $\epsilon$ is the error term associated with the kth individual in the jth society and ith genetic cluster. This model was used to test the null hypothesis of no differences among means of the concomitants age, weight, height, and body mass index (BMI) among societies within and among genetic clusters. We used Scheffe's multiple comparisons procedure (Neter et al., 1985) to make specific a posteriori pairwise comparisons among genetic clusters of concomitant means.

We used multiple regression models (Neter et al., 1985) to study in detail the independent relative contribution of variation in age, age ${ }^{2}$, weight, height, and body mass index (BMI), wt $[\mathrm{kg}] / \mathrm{ht}[\mathrm{cm}]^{2}$ ) to variation in systolic and diastolic BPs in each society. Conditional on age and age ${ }^{2}$, multiple regression models of the relative contribution of the linear effects of height and weight together versus BMI to variation in systolic and diastolic BPs indicated that in general height and weight together contributed about equally, or more, than BMI to the total coefficient of determination for most societies. Consequently, we used age, age ${ }^{2}$, height, and weight as concomitants in all subsequent analyses. We tested the null hypothesis of homogeneity of the regression on concomitants among societies within and among genetic clusters using the analysis of covariance (Neter et al., 1985).

Since there was significant heterogeneity in slopes of concomitants among societies 
within and among genetic clusters (see Results), we adjusted systolic and diastolic BPs for concomitants, using the following strategy, for each survey and sex separately: We first regressed dependent variables on concomitant variables for each society separately. The mean systolic and diastolic BP for each society was then added back to the respective residuals of the regressions. There was still variability in $\mathrm{BP}$ among individuals of societies within genetic clusters because of concomitants. Consequently, we regressed dependents on concomitants for each genetic cluster separately. The mean systolic and diastolic BPs for each genetic cluster was then added back to the respective residuals of the regressions. To remove the remaining variability among individuals of genetic clusters caused by concomitants, we regressed dependents on concomitants for all individuals and added the grand mean of systolic and diastolic BPs back to the respective residuals. It is these adjusted systolic and diastolic BPs that were considered in the primary analyses of the effects of genetic distance and degree of acculturation. This adjustment preserves the means for survey, sex, and genetic clusters, with only slight changes in original means of societies caused by nesting of societies within genetic clusters.

We used the NANOVA in equation 1 above to test the null hypothesis of no differences in mean systolic or diastolic BP among societies within and among genetic clusters. Now $Y_{i j k}$ in the model represents BP phenotype adjusted for concomitants. We used Scheffe's multiple comparisons procedure to make specific a posteriori pairwise comparisons among means of genetic clusters. We then used Bartlett's tests for homogeneity of variances (Neter et al., 1985) to test the null hypotheses of homogeneity of variances in systolic and diastolic BPs among societies within and among genetic clusters.

We used Kendall's tau (Sokal and Rohlf, 1981) to test the null hypothesis of no differences in ranks of mean systolic and diastolic BP and degree of acculturation among societies, ignoring cluster membership in survey 1. We also compared ranks of mean systolic and diastolic BPs among societies within genetic clusters, but performed no statistical tests because of only three societies within each of the Bougainville and Malaita clusters. Finally, we tested the null hypothesis of no differences in relationship (correlation) between adjusted systolic and diastolic BPs among societies within and among genetic clusters with tests of heterogeneity of correlations (Sokal and Rohlf, 1981).

\section{RESULTS \\ Samples and concomitants}

Sample sizes and mean age, weight, height, and BMI for each survey, sex, genetic cluster and society are presented in Table 2. For survey 1, sample sizes for males ranged from 74 for Nasioi to 188 for Ontong Java and for females from 83 for Nasioi to 251 for Ontong Java (Table 2). For survey 3 , sample sizes for males ranged from 33 for Lau to 158 for Ontong Java and for females from 49 for Lau to 243 for Ontong Java (Table 2). There was very little overall change in concomitant means over the 14-19 year interval between surveys 1 and 3 , with the exception of an average increase of about $4 \mathrm{~kg}$ body weight.

Results of NANOVAs comparing concomitants among societies within and among genetic clusters are presented in Table 3 . There were significant differences in means among genetic clusters for every concomitant and, except for height of males and age of females in survey 1 , among societies within genetic clusters for both surveys and sexes. Some differences were also observed among societies within the Bougainville and Malaita clusters, but they were not consistent for all concomitants, sexes, or surveys.

Comparisons of survey changes in demographic and anthropometric relationships among societies and genetic clusters are presented in Tables 2 and 3. The Ontong Java sample was taller and generally heavier than the other groups, although the Lau from the Malaita cluster approximate their BMI values at that time. In the interval between the two surveys, the great difference was in weight gain, with the Ontong Java women averaging a $12 \mathrm{~kg}$ increase over 14 years compared with a $7 \mathrm{~kg}$ gain over 18 years for the Lau women. In men, the increase was 7 and $8 \mathrm{~kg}$ in the Ontong Java and Lau, respectively. While other group means for weight increase during this interval (with the exception of the Baegu), none were close to these values. In height, the increases were substantial in individual cases (e.g., Ontong Java males and females with $3 \mathrm{~cm}$ increases), especially considering the short time interval and the semilongitudinal nature of the samples. In age structure, the major shift is the significantly older composition of the Ontong Java sample in survey 3 , as expected. 


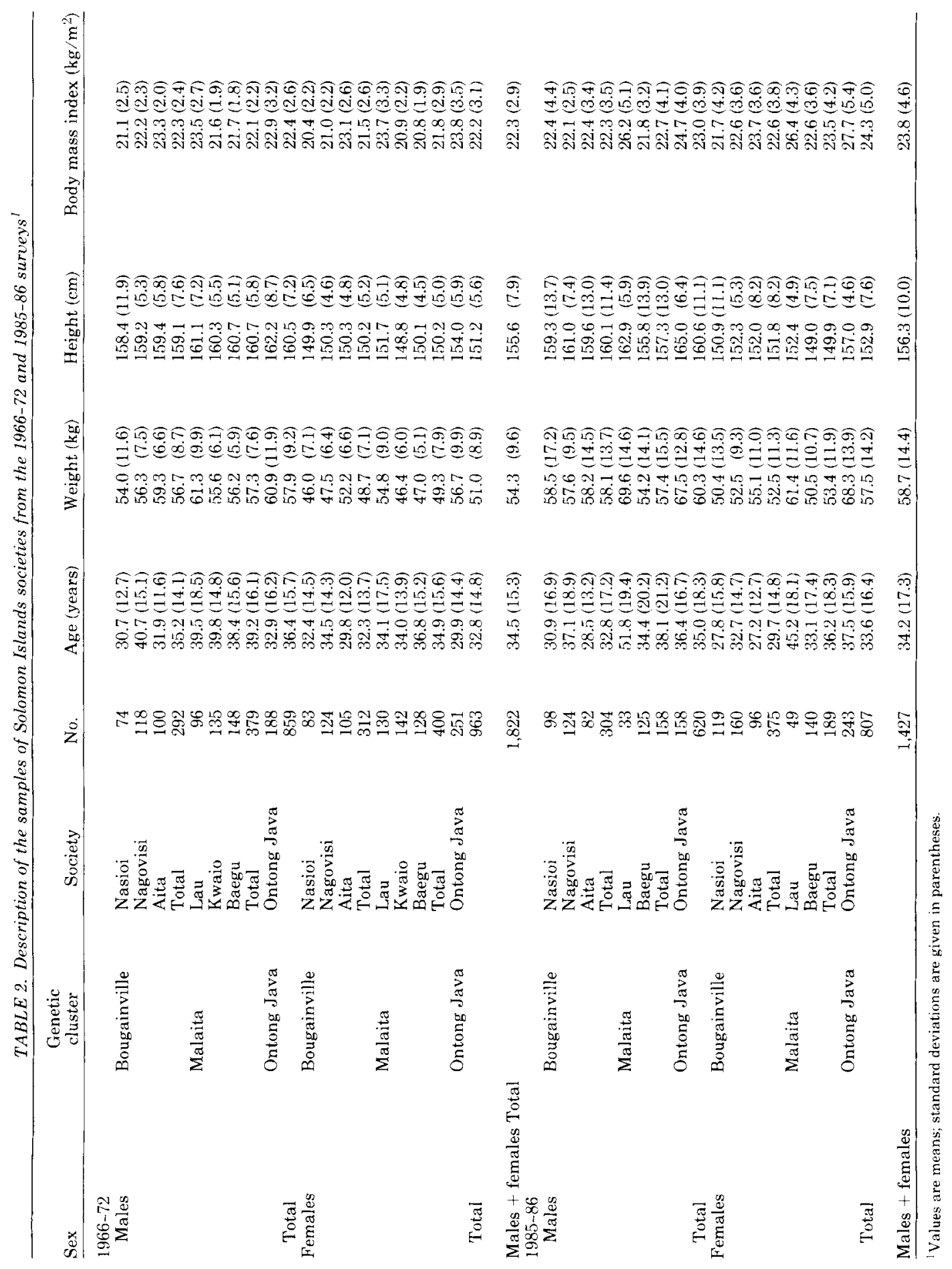




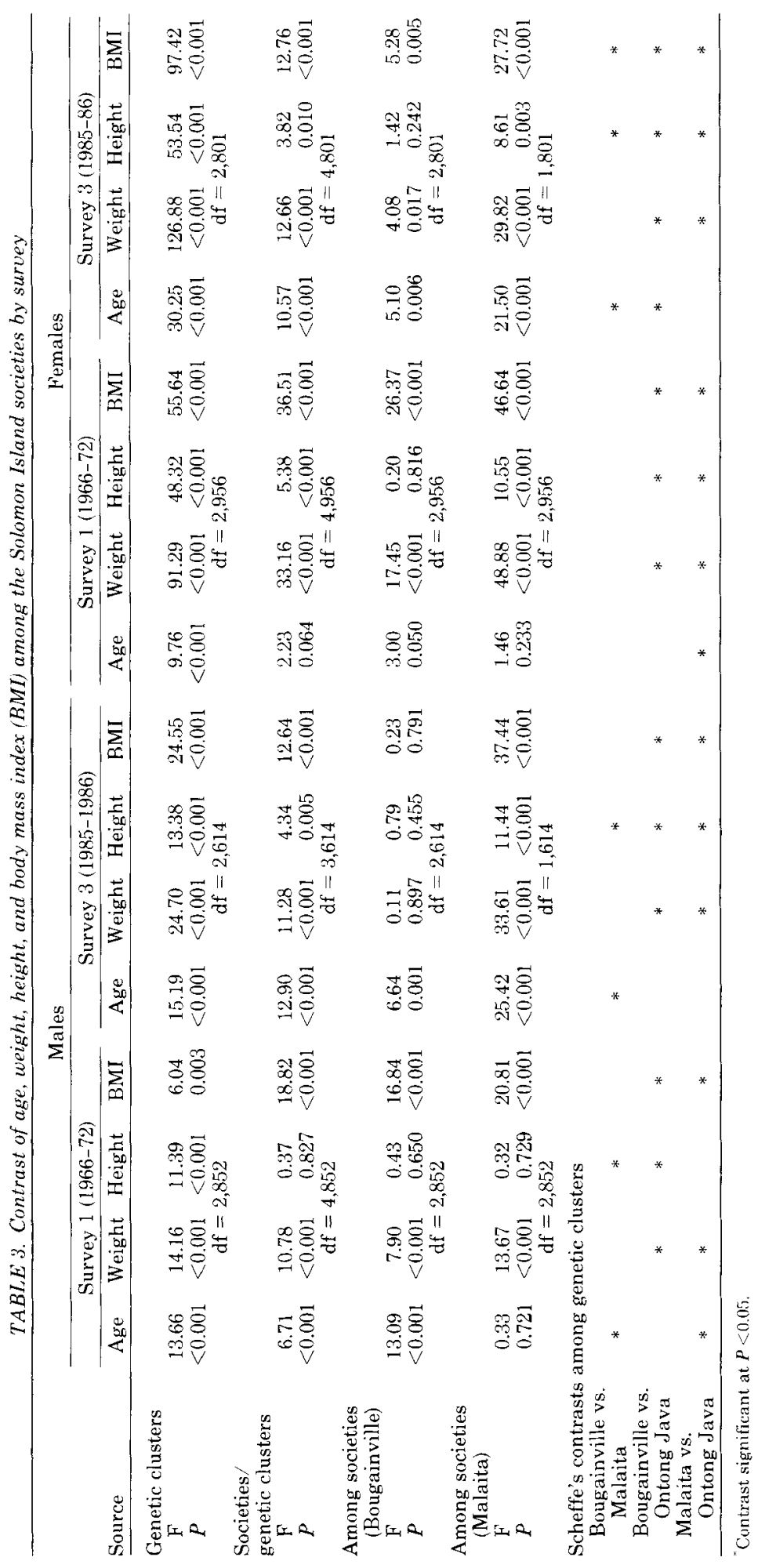




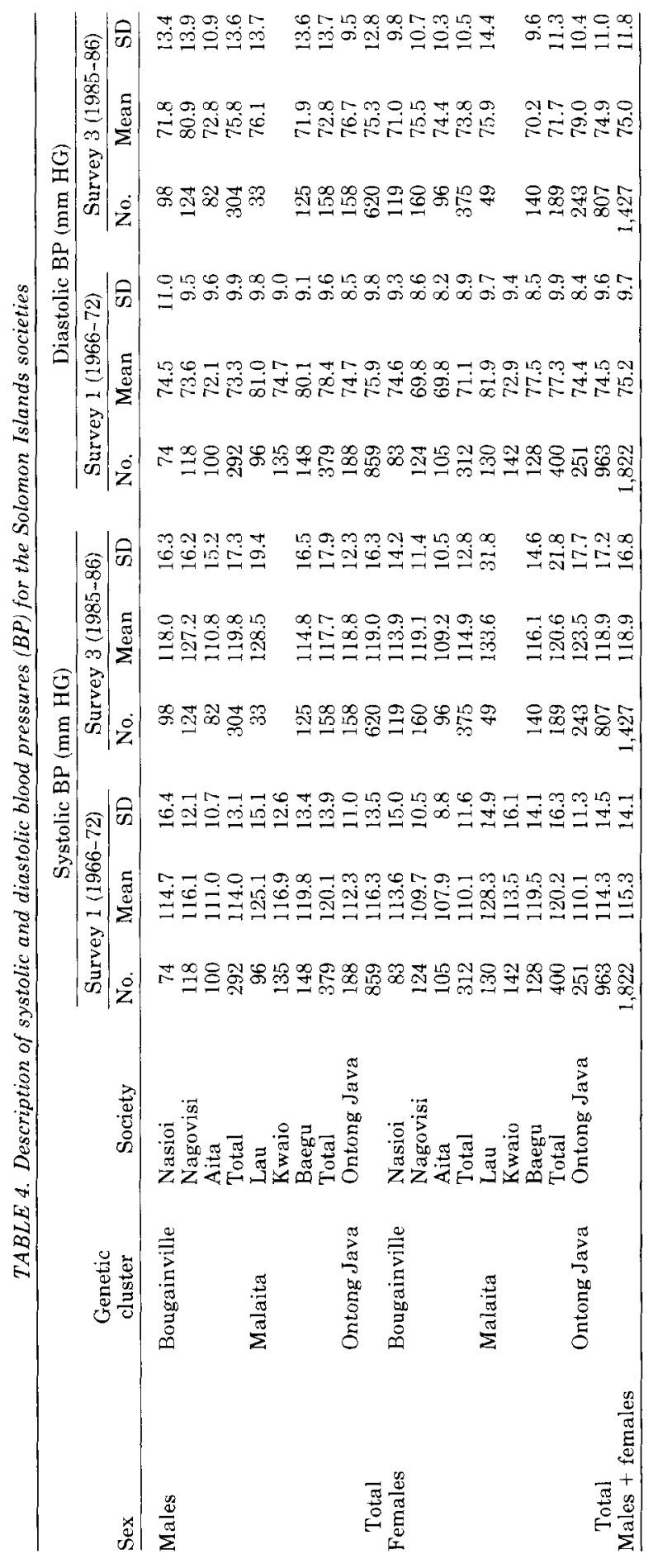




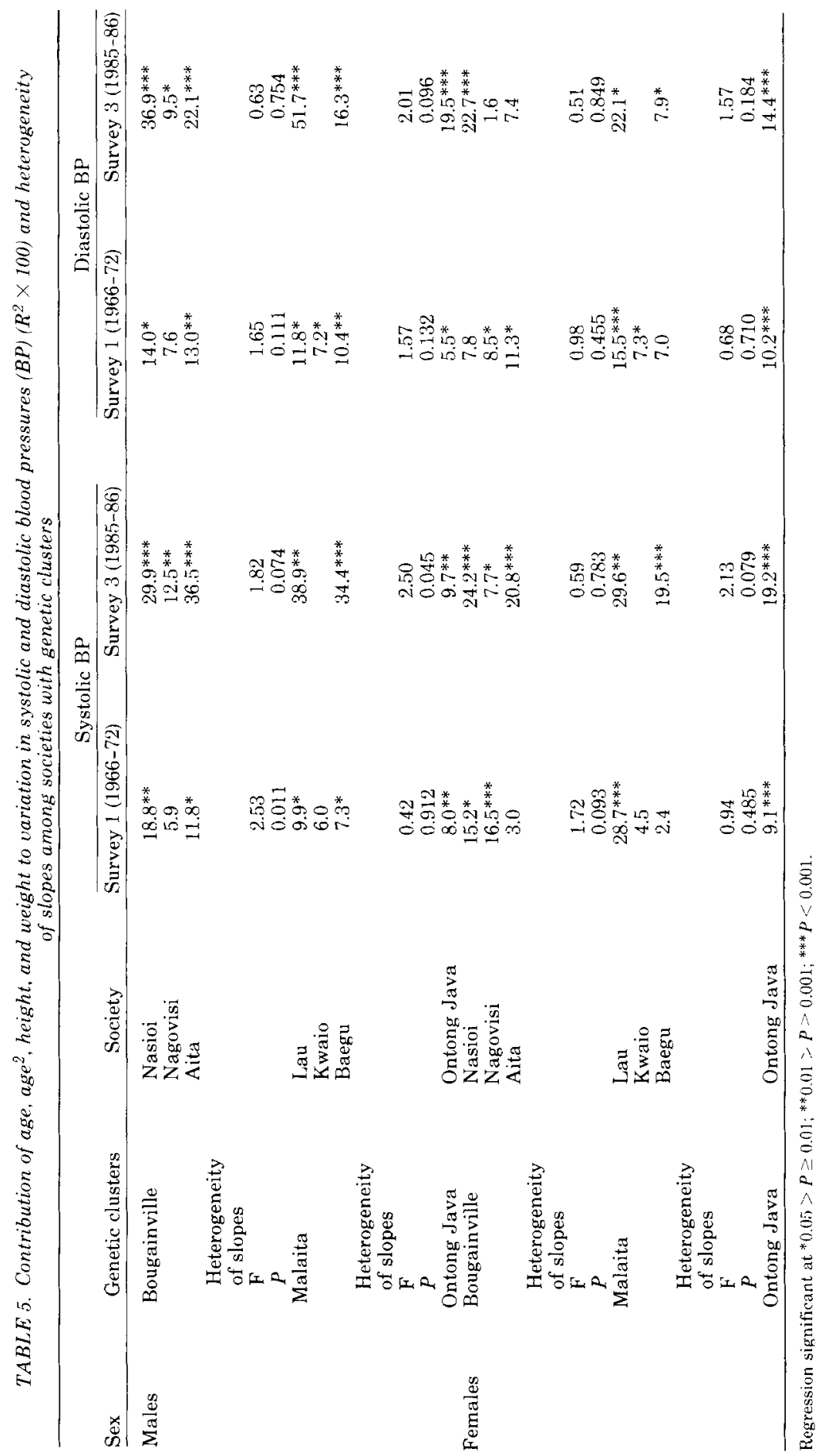


Recall that Ontong Java underwent quite extreme acculturation in the interval between surveys 1 and 3 , while the Lau, who were relatively acculturated in survey 1 , have not subsequently acculturated so dramatically. It is interesting to note that the Bougainville groups are generally the smallest and have low BMI values in both surveys, especially the most acculturated Nasioi and Nagovisi. They have become taller but not much heavier. This is in contrast with the Lau and Ontong Javanese, whose increased acculturation has been accompanied by dramatic weight gain. The Baegu, the least acculturated group in survey 3 , show relatively little change and even a decrease in some values.

\section{Blood pressure}

A description of unadjusted systolic and diastolic BP means and standard deviations (SD) for the Solomon Islands societies is presented in Table 4. There was an increase in overall mean systolic $\mathrm{BP}$ of $4 \mathrm{~mm} \mathrm{Hg}$ between the surveys, while mean diastolic $\mathrm{BP}$ did not change. Males in general had slightly higher mean systolic BPs and about the same diastolic BPs compared with females in the first survey, while in the third survey both sexes had about the same mean systolic and diastolic BPs.

Contribution of concomitants. Variations in systolic and diastolic $B P_{s}$, within societies and explained by age, age ${ }^{2}$, height, and weight, are presented in Table 5. Although the range of variability in systolic BP explained was similar in the two surveys, five of six societies of males and four of six societies of females showed dramatic increases in the contributions in the third survey (the Kwaio were not included in these comparisons since they were not resurveyed). These trends were not concordant across sex within societies. The contributions did not change between surveys for Ontong Java males and Lau females. For these two societies, contributions remained low for Ontong Java males ( 8 to $10 \%$ ) and high for Lau females (29 to $30 \%$ ). Further, there was about a $50 \%$ decrease in the contributions for Nagovisi females between the first and third surveys. Similar results were observed for diastolic BP. Slopes of relationships between concomitants and systolic and diastolic BPs were generally homogeneous among societies within genetic clusters, but not in all cases.

It is notable that concomitants did not play a significant role in determining interindi- vidual variability of systolic and diastolic $B P$ for some of the societies (Table 5). For systolic BP, those societies were males, Nagovisi; females, Aita, Kwaio, and Baegu in survey 1. For diastolic BP, those societies were survey $1-$ males, Nagovisi and Nasioi; females, Baegu; and survey 3-females, Nagovisi and Aita. There were no general trends in these relationships among societies within genetic clusters or sex from one survey to the next.

Variations in systolic and diastolic BP within genetic clusters, ignoring society differences and explained by age, age ${ }^{2}$, height, and weight, are presented in Table 6 . Unlike the mixed results observed among societies within genetic clusters, there were dramatic increases in the contribution of concomitants for all genetic clusters and both sexes with increasing acculturation between the surveys. In contrast, only males showed dramatic increases in contributions of concomitants to diastolic BP variation with increasing acculturation. Among females, the Bougainville and Ontong Javanese, but not Malaita, showed increases in contributions with increasing acculturation. In addition, the observed increases were not as large as those for males. For systolic BP, slopes were significantly heterogeneous for all but males in survey 1. For diastolic BP, slopes were significantly heterogeneous for both males and females in survey 1 , but not survey 3 .

Mean adjusted systolic and diastolic BPs. Results of NANOVAs comparing means of adjusted systolic and diastolic BPs among societies and genetic clusters are presented in Table 7 and Figures 1-3. For males in survey 1 , there were significant differences in mean systolic and diastolic BPs among societies within and among genetic clusters; the mean adjusted BPs for Malaita were significantly higher than the other two clusters (Table 7; Fig. 3A,C). Increases in acculturation in survey 3 resulted in the disap. pearance of differences among genetic clusters for males for both systolic and diastolic BPs despite continued significant heterogeneity in means among societies within genetic clusters, including both the Bougainville and the Malaita genetic clusters (Table 7). These differences for males are reflected in only $2 \mathrm{~mm} \mathrm{Hg}$ differences in mean adjusted systolic BP and $3-4 \mathrm{~mm} \mathrm{Hg}$ differences in mean adjusted diastolic BP among genetic clusters in survey 3 compared with 6 and $5 \mathrm{~mm} \mathrm{Hg}$ differences, respectively, in survey 1 (Table 4 ; Fig. $3 \mathrm{~A}, \mathrm{C}$ ). 
TABLE 6. Contribution of age, age ${ }^{2}$, height, and weight to variation in systolic and diastolic blood pressures (BP) $\left(R^{2} \times 100\right)$ and heterogeneity of slopes among genetic clusters ignoring society differences

\begin{tabular}{|c|c|c|c|c|c|}
\hline \multirow[b]{2}{*}{ Sex } & \multirow[b]{2}{*}{ Genetic cluster } & \multicolumn{2}{|c|}{ Systolic BP } & \multicolumn{2}{|c|}{ Diastolic BP } \\
\hline & & Survey 1 (1966-72) & Survey $3(1985-86)$ & Survey $1(1966-72)$ & Survey $3(1985-86)$ \\
\hline \multirow[t]{5}{*}{ Males } & Bougainville & $4.8^{* *}$ & $21.3^{* * * *}$ & $5.5^{* * *}$ & $19.3^{* * * *}$ \\
\hline & Malaita & $10.6 * * *$ & $37.9 * * *$ & $8.4^{* * *}$ & $20.6^{* * *}$ \\
\hline & $\begin{array}{l}\text { Ontong Java } \\
\text { Heterogeneity } \\
\text { of slopes }\end{array}$ & $8.0^{* *}$ & $9.7^{* *}$ & $5.5^{*}$ & $19.5 * * *$ \\
\hline & F & 1.73 & 2.71 & 2.90 & 0.86 \\
\hline & $P$ & 0.089 & 0.006 & 0.003 & 0.553 \\
\hline \multirow[t]{5}{*}{ Females } & Bougainville & $8.1^{* * *}$ & $15.0^{* * * *}$ & $5.6^{* *}$ & $9.0^{* * * *}$ \\
\hline & Malaita & $17.6^{* * *}$ & $30.5 * * *$ & $15.7^{* * *}$ & $15.0^{* * * *}$ \\
\hline & $\begin{array}{l}\text { Ontong Java } \\
\text { Heterogeneity } \\
\text { of slopes }\end{array}$ & $9.1 * * *$ & $19.2^{* * * *}$ & $10.2^{* * *}$ & $14.4^{* * *}$ \\
\hline & $\mathrm{F}$ & 4.61 & 3.12 & 3.72 & 1.50 \\
\hline & $P$ & $<0.001$ & 0.002 & $<0.001$ & 0.153 \\
\hline
\end{tabular}

Regression significant at $* 0.05>P \geq 0.01 ; * 0.01>P \geq 0.001 ; * * * P<0.001$

TABLE 7. Contrast of age, age ${ }^{2}$, weight, and height adjusted systolic and diastolic blood pressures (BP)

\begin{tabular}{|c|c|c|c|c|c|c|c|c|}
\hline \multirow[b]{3}{*}{ Source } & \multicolumn{4}{|c|}{ Males } & \multicolumn{4}{|c|}{ Females } \\
\hline & \multicolumn{2}{|c|}{ Systolic BP } & \multicolumn{2}{|c|}{ Diastolic BP } & \multicolumn{2}{|c|}{ Systolic BP } & \multicolumn{2}{|c|}{ Diastolic BP } \\
\hline & $1966-72$ & $1985-86$ & $1966-72$ & $1985-86$ & $1966-72$ & $1985-86$ & $1966-72$ & $1985-86$ \\
\hline \multicolumn{9}{|l|}{ Genetic clusters } \\
\hline $\mathrm{F}$ & 31.78 & 0.72 & 26.17 & 1.91 & 68.30 & 26.45 & 40.75 & 13.92 \\
\hline$P$ & $<0.001$ & 0.487 & $<0.001$ & 0.149 & $<0.001$ & $<0.001$ & $<0.001$ & $<0.001$ \\
\hline df & 2,812 & 2,578 & & & 2,916 & 2,765 & & \\
\hline \multicolumn{9}{|l|}{$\begin{array}{l}\text { Societies/ } \\
\text { genetic clusters }\end{array}$} \\
\hline F & 5.95 & 23.85 & 8.05 & 12.29 & 16.06 & 15.83 & 14.36 & 5.06 \\
\hline$P$ & $<0.001$ & $<0.001$ & $<0.001$ & $<0.001$ & $<0.001$ & $<0.001$ & $<0.001$ & 0.002 \\
\hline $\mathrm{df}$ & 4,812 & 3,578 & & & 4,916 & 3,765 & & \\
\hline \multicolumn{9}{|l|}{$\begin{array}{l}\text { Among societies } \\
\text { (Bougainville) }\end{array}$} \\
\hline $\mathrm{F}$ & 2.81 & 29.23 & 1.10 & 17.59 & 3.06 & 12.68 & 8.33 & 5.80 \\
\hline$P$ & 0.061 & $<0.001$ & 0.333 & $<0.001$ & 0.047 & $<0.001$ & $<0.001$ & 0.003 \\
\hline$d f$ & 2,812 & 2,578 & & & 2,916 & 2,765 & & \\
\hline \multicolumn{9}{|l|}{ Among societies } \\
\hline $\mathrm{F}$ & 9.10 & 13.10 & 15.00 & 1.69 & 29.05 & 22.12 & 20.40 & 3.58 \\
\hline$P$ & $<0.001$ & $<0.001$ & $<0.001$ & 0.194 & $<0.001$ & $<0.001$ & $<0.00 \mathrm{l}$ & 0.059 \\
\hline$d f$ & 2,812 & 1,578 & & & 1,916 & 1,765 & & \\
\hline \multicolumn{9}{|c|}{ Scheffe's contrasts among genetic clusters } \\
\hline Bougainville vs. & & & & & & & & \\
\hline Malaita & * & & * & * & * & $*$ & * & * \\
\hline $\begin{array}{c}\text { Bougainville vs. } \\
\text { Ontong Java }\end{array}$ & & & & & & * & * & * \\
\hline Malaita vs. & & & & & & & & \\
\hline Ontong Java & * & & * & * & * & & * & * \\
\hline
\end{tabular}

* Contrast significant at $P<0.65$.

For females in both surveys there was significant heterogeneity of means of systolic and diastolic BPS among societies within and among genetic clusters (Table 7; Figure 3B,D). In survey 1 , the adjusted systolic BP mean for Malaita females was sig- nificantly higher than that for the other two clusters, while the adjusted diastolic BP mean for Malaita females was significantly higher than that for Ontong Java, which was significantly higher than that for Bougainville. The differences among genetic clusters 


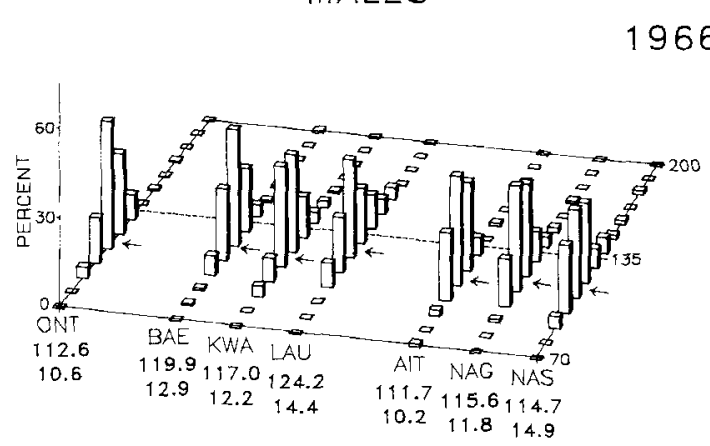

$1966-72$

$1985-86$
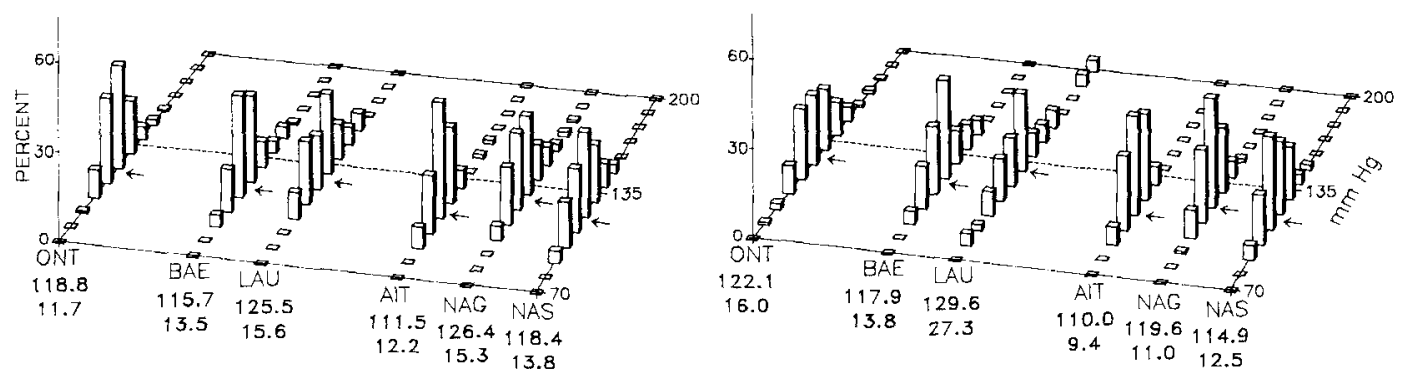

Fig. 1. Description of adjusted systolic blood pressure (BP) for the Solomon Islands societies. NAS, Nasioi; NAG, Nagovisi; AIT, Aita; LAU, Lau; KWA, Kwaio; BAE, Baegu; ONT, Ontong Java. Arrows represent mean adjusted BP for each society. Numbers below society abbreviations are mean and standard deviation, respectively.

in survey 3 were much less than in survey 1 (Fig. 3B,D), although still significant, as indicated by large decreases in $\mathrm{F}$ statistics.

Ignoring cluster membership, the survey 1 differences in mean systolic and diastolic BPs among societies were not significantly correlated (Kendall's tau) with initial differences among societies in degree of acculturation for either males or females (Tables 1, 4), suggesting these differences must be attributable to other factors than the degree of acculturation at that time.

Variances of adjusted systolic and diastolic BPs. Comparisons of adjusted interindividual variances among societies within genetic clusters is presented in Table 8 . The estimates of the interindividual systolic $B P$ variances were significantly heterogeneous only among societies of the Bougainville cluster for both sexes in survey 1 and for females in both Bougainville and Malaita clusters in survey 3. Interindividual variances of diastolic BP were significantly het- erogeneous among societies only for Malaita females in survey 3 . In general, there were striking increases in systolic BP variances for survey 3 compared with survey 1 for all societies and sexes except the Nasioi. Notable are the Lau females, who showed a fourfold increase. This increase was largely due to two older, hypertensive individuals (Fig. 1). Diastolic BP variances increased with increasing acculturation between surveys for all surveys and sexes except Nasioi females (Fig. 2). Some of these increases were dramatic, including roughly twofold increases by Nagovisi and Baegu males and by Lau females.

Comparisons of interindividual variances of adjusted systolic and diastolic BPs among genetic clusters is presented in Table 9 . For males and females in both surveys, there was significant heterogeneity of systolic BP variances among genetic clusters. For males, there was significant heterogeneity of diastolic BP variances among genetic clusters 

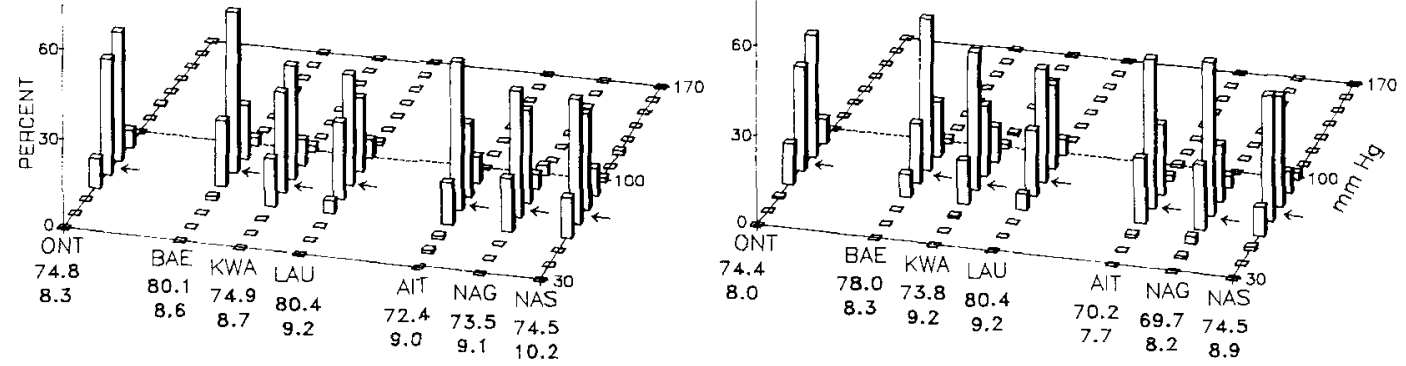

$1985-86$
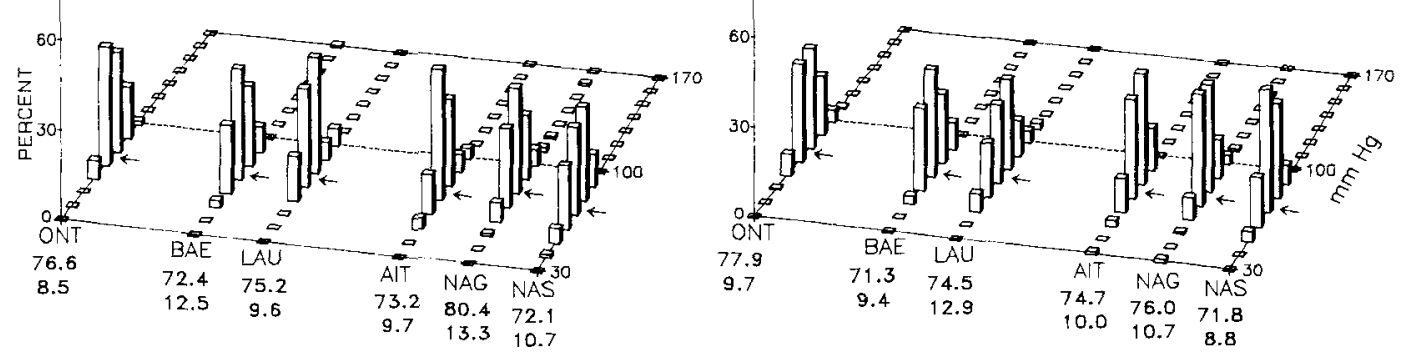

Fig. 2. Description of adjusted diastolic blood pressure for the Solomon Islands societies. Abbreviations, arrows, and numbers as in Figure 1.

for survey 3 but not survey 1 , whereas for females there was significant heterogeneity for survey 1 but not survey 3 . In every genetic cluster, survey 3 estimates of interindividual adjusted systolic BP variance represent increases from corresponding values in survey 1. Adjusted diastolic BP interindividual variances were again generally less than systolic BP.

Correlations between adjusted systolic and diastolic BPs. There were universal decreases in correlations between adjusted systolic and diastolic BP among societies and genetic clusters from survey 1 to survey 3 (Tables 10 and 11). For societies within genetic clusters the correlations were significantly heterogeneous for Malaita males in survey 3 and for Bougainville and Malaita females in survey 1 (Table 10). Among genetic clusters, there was significant heterogeneity of correlations only for males in survey 1 (Table 11 ).

\section{DISCUSSION}

Our study reveals the underlying problems many researchers in the area of biosta- tistics of blood pressure ignore at their peril. All too often, it is assumed that the relationships between dependent and independent variables are homogeneous from one population to the next or from one environment to the next. We have presented here examples of how heterogeneous such relationships can be, even in a series of surveys in which there was substantial overlap in subjects and relatively similar ethnic and cultural backgrounds among the populations.

The most striking feature of this study was the enormous heterogeneity of the distributions of BP in this set of rapidly acculturating and genetically diverse societies from the Solomon Islands. Clearly, in a multifactorial trait such as BP, both genetic and environmental factors are involved. At the level of individual societies the contributions of age, age $^{2}$, height, and weight to systolic and diastolic BP variability and patterns of mean adjusted systolic and diastolic BPs among societies within genetic clusters were complex with respect to increasing acculturation. This heterogeneity in the contribution of concomitants to these distributions can be 
Males
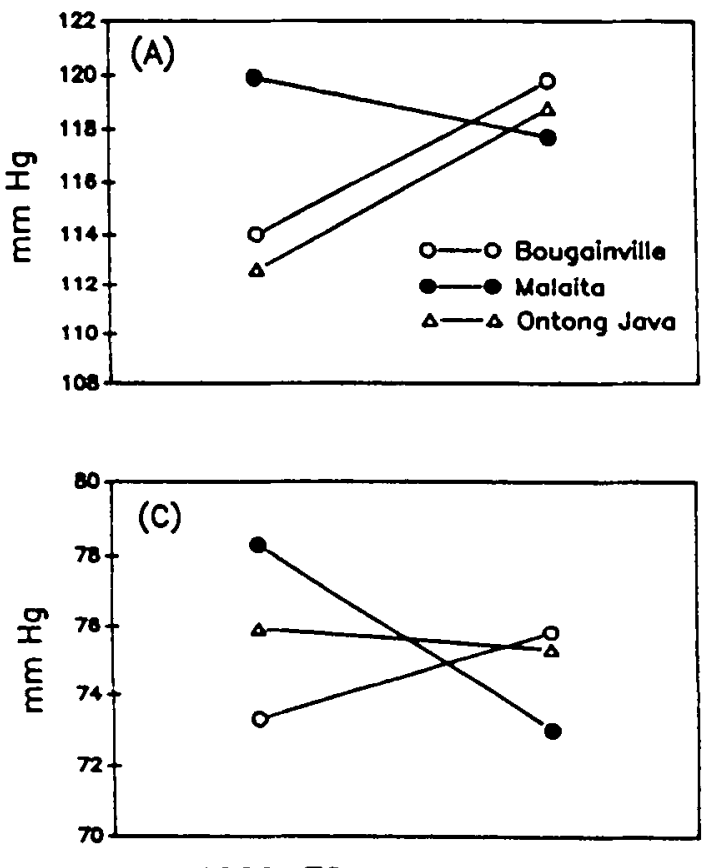

$1966-72$

1985-86

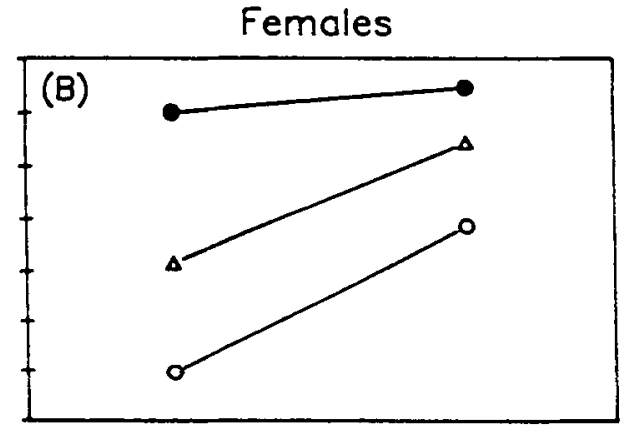

(D)

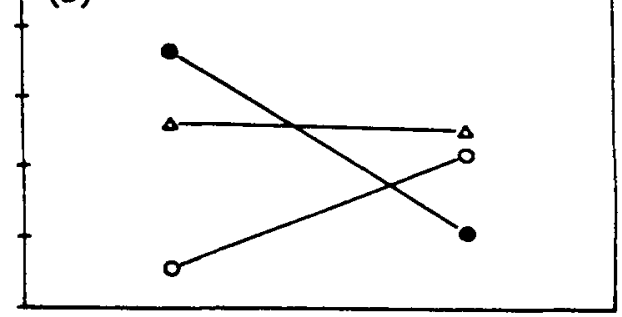

1966-72

1985-86

Fig. 3. Description of mean adjusted blood pressure (BP) for the genetic clusters of Solomon Islands societies with increasing acculturation from survey 1 to survey 3. A: Males, systolic BP. B: Females, diastolic BP. C: Males, diastolic BP. D: Females, diastolic BP.

due differences in sampling and demographics as well as real differences in regression relationships. It is impossible to distinguish among these explanations. This great heterogeneity in responses to acculturation, however, suggests that there must be substantial and significant heterogeneity in environments experienced by individual societies. Many studies of primitive societies undergoing increased acculturation have focused on the role of biological factors, including diet, exercise, stature, salt intake and infectious disease, and on psychosocial factors in the intrapopulation distribution of $\mathrm{BP}$ (Scotch and Geiger, 1963; Henry and Cassel, 1969; Cassel, 1975; Ward, 1983; James, 1987). Ward et al. (1979) in a study of premigrant Tokelauans noted heterogeneity among atolls in contributions of concomitants, including age and weight, to variability in BP. They attributed this heterogeneity to differences in environments among atolls.

The influence of acculturation became more lucid at the genetic clusters level. With the rapid increase in acculturation in all societies recovered in survey 3 , concomitants became much more important in explaining $\mathrm{BP}$ variability. Further, there were dramatic changes in mean adjusted BP. Differences among genetic clusters disappeared for males and decreased dramatically for females (Fig. 3A-D). The variances of systolic and diastolic BPs, which had been heterogeneous across genetic clusters and not related to acculturation rank, all increased markedly. There are four explanations for these increases in variance: 1) Increases in variance such as these are expected given the varying influences of acculturation among individuals, e.g., changes associated with entry into the world cash economy are not distributed equally among individuals (Friedlaender et al., 1987). 2) Increased variances in some societies may be related to increased proportions of older individuals, who are more sensitive to environmental variation. Some societies shifted demographically, showing increased mean age in 
$T A B L E$ 8. Interindividual systolic and diastolic blood pressures (BP) variances for societies within genetic clusters after adjustment for contomitants and Bartlett's tests $(B)$ for homogeneity of variances among societies within genetic clusters

\begin{tabular}{|c|c|c|c|c|c|c|}
\hline \multirow[b]{2}{*}{ Sex } & \multirow{2}{*}{$\begin{array}{l}\text { Genetic } \\
\text { Cluster }\end{array}$} & \multirow[b]{2}{*}{ Society } & \multicolumn{2}{|c|}{ Systolic BP } & \multicolumn{2}{|c|}{ Diastolic BP } \\
\hline & & & $1966-72$ & $1985-86$ & $1966-72$ & $1985-86$ \\
\hline \multirow[t]{13}{*}{ Males } & Bougainville & Nasioi & 220.7 & 190.4 & 104.9 & 115.2 \\
\hline & & Nagovisi & 139.2 & 234.9 & 83.0 & 176.2 \\
\hline & & Aita & 103.3 & 148.9 & 81.2 & 93.8 \\
\hline & $\begin{array}{l}\text { Homogeneity } \\
\text { of variances }\end{array}$ & & & & & \\
\hline & $\mathrm{B}$ & & 12.54 & 1.12 & 0.61 & 3.23 \\
\hline & $P$ & & 0.002 & 0.291 & 0.738 & 0.072 \\
\hline & Malaita & Lau & 208.7 & 243.2 & 85.3 & 91.4 \\
\hline & & Kwaio & 148.7 & & 75.2 & \\
\hline & & Baegu & 167.4 & 182.0 & 74.7 & 156.1 \\
\hline & $\begin{array}{l}\text { Homogeneity } \\
\text { of yariances }\end{array}$ & & & & & \\
\hline & B & & 3.29 & 1.12 & 0.61 & 3.23 \\
\hline & $P$ & & 0.193 & 0.291 & 0.738 & 0.072 \\
\hline & Ontong Java & Ontong Java & 112.5 & 136.5 & 68.4 & 72.2 \\
\hline \multirow[t]{13}{*}{ Females } & Bougainville & Nasioi & 191.4 & 156.8 & 79.1 & 77.5 \\
\hline & & Nagovisi & 94.6 & 120.3 & 67.6 & 114.4 \\
\hline & & Aita & 77.3 & 89.0 & 59.9 & 100.4 \\
\hline & $\begin{array}{l}\text { Homogeneity } \\
\text { of variances }\end{array}$ & & & & & \\
\hline & B & & 22.02 & 8.25 & 1.78 & 5.00 \\
\hline & $P$ & & $<0.001$ & 0.016 & 0.410 & 0.082 \\
\hline & Malaita & Lau & 167.4 & 744.6 & 84.0 & 166.5 \\
\hline & & Kwaio & 250.8 & & 84.5 & \\
\hline & & Baegu & 198.2 & 190.6 & 69.2 & 89.3 \\
\hline & $\begin{array}{l}\text { Homogeneity } \\
\text { of variances }\end{array}$ & & & & & \\
\hline & $\mathrm{B}$ & & 5.58 & 38.53 & 1.63 & 7.52 \\
\hline & $P$ & & 0.061 & $<0.001$ & 0.443 & 0.006 \\
\hline & Ontong Java & Ontong Java & 116.2 & 255.0 & 63.6 & 93.9 \\
\hline
\end{tabular}

TABLE 9. Interindividual systolic and diastolic blood pressures (BP) variances for genetic clusters after adjustment for concomitants and Bartlett's tests $(B)$ for homogeneity of variances among genetic clusters

\begin{tabular}{|c|c|c|c|c|c|}
\hline \multirow[b]{2}{*}{ Sex } & \multirow{2}{*}{$\begin{array}{l}\text { Genetic } \\
\text { cluster }\end{array}$} & \multicolumn{2}{|c|}{ Systolic BP } & \multicolumn{2}{|c|}{ Diastolic BP } \\
\hline & & $1966-72$ & $1985-86$ & $1966-72$ & $1985-86$ \\
\hline \multirow{6}{*}{ Males } & Bougainville & 149.5 & 233.3 & 87.9 & 148.4 \\
\hline & Malaita & 177.8 & 209.3 & 83.7 & 143.3 \\
\hline & Ontong Java & 112.5 & 136.5 & 68.4 & 72.2 \\
\hline & $\begin{array}{l}\text { Homogeneity } \\
\text { of variances }\end{array}$ & & & & \\
\hline & $\mathrm{B}$ & 12.53 & 13.99 & 3.69 & 25.91 \\
\hline & $P$ & 0.002 & $<0.001$ & 0.158 & $<0.001$ \\
\hline \multirow[t]{6}{*}{ Females } & Bougainville & 116.9 & 138.3 & 71.6 & 101.8 \\
\hline & Malaita & 229.1 & 357.2 & 86.7 & 110.5 \\
\hline & $\begin{array}{l}\text { Ontong Java } \\
\text { Homogeneity }\end{array}$ & 116.2 & 255.0 & 63.6 & 93.9 \\
\hline & of variances & & & & \\
\hline & B & 54.16 & 63.33 & 7.89 & 1.41 \\
\hline & $P$ & $<0.001$ & $<0.001$ & 0.019 & 0.494 \\
\hline
\end{tabular}

survey 3, particularly the Lau and Ontong Javanese (Table 2). The only other study of $\mathrm{BP}$ variance over a broad age range showed that increased variance in systolic $B P$ is associated with age in whites in Rochester, Minnesota (Turner et al., 1989). 3) There is likely to be increased range and intensity of environmental factors acting on BP associated with increased acculturation that causes increased interindividual differences in blood pressure. This explanation may be more likely in those societies that had been 
TABLE 10. Pearson product-moment correlations between adjusted systolic and diastolic blood pressures (BP) and heterogeneity of correlations among societies within genetic clusters'

\begin{tabular}{|c|c|c|c|c|}
\hline Sex & $\begin{array}{l}\text { Genetic } \\
\text { cluster }\end{array}$ & Society & $\begin{array}{l}\text { Survey } 1 \\
(1966-72) \\
\end{array}$ & $\begin{array}{r}\text { Survey } 3 \\
(1985-86) \\
\end{array}$ \\
\hline \multirow[t]{13}{*}{ Males } & Bougainville & Nasioi & 0.76 & 0.43 \\
\hline & & Nagovisi & 0.73 & 0.41 \\
\hline & & Aita & 0.77 & 0.38 \\
\hline & $\begin{array}{l}\text { Heterogeneity of } \\
\text { correlations }\end{array}$ & & & \\
\hline & $x^{2}$ & & 0.48 & 0.16 \\
\hline & $\stackrel{P}{P}$ & & 0.787 & 0.923 \\
\hline & Malaita & Lau & 0.71 & 0.30 \\
\hline & & Kwaio & 0.74 & \\
\hline & & Baegu & 0.71 & 0.68 \\
\hline & $\begin{array}{l}\text { Heterogeneity of } \\
\text { correlations }\end{array}$ & & & \\
\hline & $x^{2}$ & & 0.34 & 6.50 \\
\hline & $P$ & & 0.844 & 0.011 \\
\hline & Ontong Java & Ontong Java & 0.64 & 0.58 \\
\hline \multirow[t]{13}{*}{ Females } & Bougainville & Nasioi & 0.57 & 0.55 \\
\hline & & Nagovisi & 0.47 & 0.41 \\
\hline & & Aita & 0.71 & 0.49 \\
\hline & $\begin{array}{l}\text { Heterogeneity of } \\
\text { correlations }\end{array}$ & & & \\
\hline & $x^{2}$ & & 7.94 & 2.26 \\
\hline & $\hat{P}$ & & 0.019 & 0.323 \\
\hline & Malaita & Lau & 0.59 & 0.46 \\
\hline & & Kwaio & 0.75 & \\
\hline & & Baegu & 0.62 & 0.48 \\
\hline & $\begin{array}{l}\text { Heterogeneity of } \\
\text { correlations }\end{array}$ & & & \\
\hline & $\chi^{2}$ & & 6.76 & 0.02 \\
\hline & $\hat{P}$ & & 0.034 & 0.888 \\
\hline & Ontong Java & Ontong Java & 0.62 & 0.57 \\
\hline
\end{tabular}

${ }^{1}$ In every case the correlations presented here are significantly different from zero at the 0.001 level of probability.

TABLE 11. Pearson product-moment correlations between adjusted systolic and diastolic blood pressures (BP) and heterogeneity of correlations among genetic clusters ${ }^{1}$

\begin{tabular}{llcc}
\hline Sex & $\begin{array}{c}\text { Genetic } \\
\text { cluster }\end{array}$ & $\begin{array}{c}\text { Survey 1 } \\
(1966-72)\end{array}$ & $\begin{array}{r}\text { Survey 3 } \\
(\mathbf{1 9 8 5 - 8 6 )}\end{array}$ \\
\hline Males & $\begin{array}{l}\text { Bougainville } \\
\text { Malaita }\end{array}$ & 0.75 & 0.46 \\
& Ontong Java & 0.72 & 0.60 \\
Heterogeneity of & & 0.64 & 0.57 \\
correlations & & & 4.73 \\
$\chi^{2}$ & & 5.28 & 0.094 \\
$P$ & Bougainville & 0.071 & 0.46 \\
Females & Malaita & 0.58 & 0.48 \\
& Ontong Java & 0.69 & 0.57 \\
Heterogeneity of & & 0.62 & 3.45 \\
correlations & & 6.30 & 0.178 \\
$\quad \chi^{2}$ & & 0.043 & \\
$P$ & & & \\
\hline
\end{tabular}

${ }^{1}$ In every case, the correiations presented here are significantly different from zero at the 0.001 level of probability.

the least acculturated in survey 1 since increased acculturation is more likely to expose individuals to increased numbers of environmental factors. 4) There could be in- creased numbers of environmental factors with increased acculturation.

However, the most important factors influencing BP could be present in both sur- 
veys with their effects on $B P$ increased with more intense acculturation, with some genotypes within societies being more sensitive to these environmental changes. In this case, increases in variances would be the result of genotype by environment interactions. This explanation is more likely in those societies already more acculturated in survey 1 since environmental factors affecting BP and associated with acculturation are more likely to be already present. Since we did not measure genotypes within or distinguish environmental factors among these societies, it is not possible to separate explanation 2 from 3 .

The high correlations between systolic and diastolic BPs typical of the first survey all decreased sharply with rapid acculturation to survey 3 . This trend was at least partially the result of the more intense and diverse effect acculturation had on systolic BP variances. Clearly, systolic and diastolic BPs were not perfectly correlated initially, and the decrease in correlations with increased acculturation suggests that there are differences in impacts of genes and environments upon these traits.

The relative involvement of genetic or enviromental factors in the heterogeneity of the $\mathrm{BP}$ distributions is unknown given the study design. There were, however, distinct differences among genetic clusters in mean adjusted BP in the initial survey. It is well known that there can be considerable genetic differentiation, even among local primitive societies (Neel and Ward, 1970; Ward, 1972; Rothhammer et al., 1973; Neel et al., 1974; Friedlaender, 1975; Ward and Neel, 1976; Neel, 1978) as well as ethnic and/or racial differences in BP (Barbosa et al., 1983). In our study, since ranks of society means ignoring cluster membership were unassociated with acculturation rank, it is probable that at least some of the differences among means are due to genetic differences among societies and clusters. It may be that individual environmental variables associated with overall degree of acculturation among individual societies, however, are more critical and instructive. To the extent that at least some of the initial differences in mean adjusted BP among genetic clusters are probably attributable to genetic differences, we may attribute changes observed with acculturation (Fig. 3A-D) to genotype by environment interaction ( sensu Haldane, 1946; Ward, 1985). In general, depending on its complexity, the presence of gene by envi- ronment interaction makes interpretation of the separate contributions of genetic and acculturation differences among populations to variability in $\mathrm{BP}$ much more difficult, since differences in $\mathrm{BP}$ among genetically heterogeneous populations are not consistent across environments and vice versa. Hence future studies of the causes of the observed heterogeneity among Solomon Islands populations must include measures of appropriate genotypes and individual environment exposures.

\section{ACKNOWLEDGMENTS}

This research was supported in part by NIH HLBI grants HL30428 and HL39107 and by NSF grant BNS 83-18534. We thank Martha Haviland, Jim Neel, Louis Perusse, Sharon Reilly, Ken Weiss, and three anonymous reviewers for many helpful comments on the manuscript. We also thank Chuck Carlo for the computer graphics.

\section{LITERATURE CITED}

Abbie AA, and Schroder J (1960) Blood pressures in Arnhem Land Aborigines. Med. J. Aust. 2:493-496.

Barbosa CAA, Morton NE, Wette R, Rao DC, and Krieger H (1983) Race, height, and blood pressure in Northeastern Brazil. Soc. Biol. 30:211-217.

Burns-Cox CJ, and Maclean JD (1970) Splenomegaly and blood pressure in an Orang Asii community in West Malaysia. Am. Heart J. 80:718-719.

Cassel J (1975) Studies of hypertension in migrants. In Paul O (ed.): Epidemiology and Control of Hypertension. New York: Stratton Intercontinental Medical Book Corp, pp. 41-61.

Cruz-Coke $R$ (1987) Correlation between prevalence of hypertension and degree of acculturation. J. Hypertens, 5:47-50.

Cruz-Coke R, Donoso H, and Barrera R (1973) Genetic ecology of hypertension. Clin. Sci. Mol. Med. 45: $55 \mathrm{~s}-65 \mathrm{~s}$.

Cruz-Coke R, Etcheverry R, and Nagel R (1964) Influence of migration on blood-pressure of Easter Islanders. Lancet 1:697-699.

Donnison CP (1929) Blood pressure in the African native. Lancet 1:6-7.

Friedlaender JS (1975) Patterns of Human Variation. The Demography, Genetics, and Phenetics of Bougainville Islanders. Cambridge: Harvard University Press, $252 \mathrm{pp}$.

Friedlaender JS (1990). The Solomon Islands project: Design and description. Am. J. Phys. Anthropol. (This issue).

Friedlaender JS, Howells W, and Rhoads JG (1987) The Solomon Islands Project. A Long-Term Study of Health, Human Biology, and Culture Change. Oxford: Clarendon Press, $409 \mathrm{pp}$.

Friedlaender JS, and Page LB (1987) Blood pressure changes in the survey populations. In Friedlaender JS, Howells W, and Rhoads JG (eds.): The Solomon Islands Project. A Long-Term Study of Health, Human Biology, and Culture Change. Oxford: Clarendon Press, pp. 307-326. 
Froelich JW (1987) Fingerprints as genetic markers in the Solomon Islands. In Friedlaender JS, Howells W, and Rhoads JG (eds.): The Solomon Islands Project. A Long-Term Study of Health, Human Biology, and Culture Change. Oxford: Clarendon Press, pp. 175-214.

Glanville EV, and Geerdink RA (1972) Blood pressure of Amerindians from Surinam. Am. J. Phys. Anthropol. 37:251-254.

Haldane JBS (1946) The interaction of nature and nurture. Ann. Eugen. 13:197-205.

Hanna JM, and Baker PT (1979) Biocultural correlates to the blood pressure of Samoan migrants in Hawaii Hum. Biol. 51:481-497.

Harris EF, and Bailit HL (1987) Odontometric comparisons among Solomon Islanders and other oceanic people. In Friedlaender JS, Howells W, and Rhoads JG (eds.): The Solomon Islands Project. A Long-Term Study of Health, Human Biology, and Culture Change. Oxford: Clarendon Press, pp. 215-264.

Henry JP, and Cassel JC (1969) Psychosocial factors in essential hypertension. Recent epidemiologic and animal experimental evidence. Am. J. Epidemiol. 90: $171-200$.

Hoobler SW (1965) Influence of nutrition and "acculturation" on the blood pressure levels and changes with age in the highland Guatemalan Indian. Circulation (Suppl. II) 31:116.

James SA (1987) Psychosocial precursors of hypertension: A review of the epidemiological evidence. Circulation (Suppl. I) 76:60-66.

James GD, McGarvey ST, and Baker PT (1983) The effect of modernization on spouse concordance in American Somoa. Hum. Biol. 55:643-652.

Labarthe DR (1973) Health effects of modernization in Palau. Am. J. Epidemiol. 98:161-174.

Lowenstein FW (1961) Blood-pressure in relation to age and sex in the tropics and subtropics. A review of the literature and an investigation in two tribes of Brazil Indians. Lancet 1:389-392.

Maddocks I (1961) Possible absence of essential hypertension in two complete Pacific Island populations. Lancet 2:396-399.

Mann GV, Roels OA, Price DL, and Merrill JM (1962) Cardiovascular disease in African Pygmies. A survey of the health status, serum lipids and diet of Pygmies in Congo. J Chronic Dis. 15:341-371.

Mann GV, Shaffer RD, Anderson RS, and Sandstead HH. (1964) Cardiovascular disease in the Masai. J. Atheroscler. Res. 4:289-312.

Marmot MG, and Syme SL (1976) Acculturation and coronary heart disease in Japanese-Americans. Am. J. Epidemiol. 104:225-247.

McGarvey ST, and Baker PT (1979) The effects of modernization and migration on Samoan blood pressures. Hum. Biol. 51:461-479.

McGarvey ST, and Schendel DE (1986) Blood pressure of Samoans. In Baker PT, Hanna JM, and Baker TS (eds.): The Changing Samoans. Behavior and Health in Transition. New York: Oxford University Press, pp. 350-393.

Morse WR, and Beh YT (1937) Blood pressure amongst aboriginal groups of Szechwan Province, West China. Lancet 1:966-967.

Murrill RI (1949) A blood pressure study of the natives of Ponape Island, Eastern Carolines. Hum. Biol. 21: $47-59$.

Neel JV (1978) The population structure of an Amerindian tribe, the Yanomama. Annu. Rev. Genet. 12: $365-413$.
Neel JV, Rothhammer F, and Lingoes JC (1974) The genetic structure of a tribal population, the Yanomama Indians. X. Agreement between representations of village distances based on different sets of characteristics. Am. J. Hum. Genet. 26:281-303.

Neel JV, and Ward RH (1970) Village and tribal genetic distances among American Indians, and the possible implications for human evolution. Proc. Natl. Acad Sci. U.S.A. 65:323-330.

Neter J, Wasserman W, and Kutner MH (1985) Applied Linear Statistical Models, 2nd ed. Homewood: Richard D. Irwin, Inc., $1127 \mathrm{pp}$.

Oliver WJ, Cohen EL, and Neel JV (1975) Blood pressure, sodium intake, and sodium related hormones in the Yanomomo Indians, a "no-salt" culture. Circulation 52:146-151.

Page LB (1976) Epidemiologic evidence on the etiology of human hypertension and its possible prevention. Am. Heart J. 91:527-534.

Page LB (1980) Hypertension and atherosclerosis in primitive and acculturating societies. In Hypertension Update: Mechanisms, Epidemiology, Evaluation, Management. Bloomfield, NJ: Health Learning Systems, Inc., pp. 1-12.

Page LB, Damon A, and Moellering RC Jr. (1974) Antecedents of cardiovascular disease in six Solomon Islands societies. Circulation 49:1132-1146.

Poulter NR, Khaw KT, Mugambi M, Peart WS, Rose G, and Sever $\mathrm{P}$ (1985) Blood pressure patterns in relation to age, weight, and urinary electrolytes in three Kenyan communities. Trans. Roy. Soc. Trop. Med. Hygiene 79:389-392

Prior IAM, Evans JG, Harvey HPB, Davidson F, and Lindsey M (1968) Sodium intake and blood pressure in two Polynesian populations. N. Engl. J. Med 279:515-520.

Prior IAM, Stanhope JM, Evans JG, and Salmond CE (1974) The Tokelau Island migrant study. Int. J. Epidemiol. 3:225-232

Rhoads JG, and Friedlaender JS (1987) Blood polymorphism variation in the Solomon Islands. In Friedlaender JS, Howells W, and Rhoads JG (eds.): The Solomon Islands Project. A Long-Term Study of Health, Human Biology, and Culture Change. Oxford: Clarendon Press, pp. 125-154.

Rothhammer F, Neel JV, Da Rocha F, and Sundling GY (1973) The genetic structure of a tribal population, the Yanomama Indians. VIII. Dermatoglyphic differences among villages. Am. J. Hum. Genet. 25:152-166.

SAS Institute (1985) SAS User's Guide, Version 5. Cary, NC: SAS Institute, Inc.

Scotch NA, and Geiger HJ (1963) The epidemiology of essential hypertension. A review with special attention to psychologic and sociocultural factors. II: Psychologic and sociocultural factors in etiology. J. Chronic Dis. 16:1183-1213.

Shaper AG, Wright DH, and Kyobe J (1969) Blood pressure and body build in three nomadic tribes of Northern Kenya. East Afr. Med. J. 46:273-281.

Sokal RR, and Rohlf FJ (1981) Biometry, 2nd ed. New York: W.H. Freeman and Company, $859 \mathrm{pp}$

Thomas WA (1927) Health of a carnivorous race. A study of the Eskimo. J.A.M.A. 88:1559-1560.

Truswell AS, Kennelly BM, Hansen JDL, and Lee RB (1972) Blood pressures of !Kung bushmen in Northern Botswana. Am. Heart J. 84:5-12.

Turner ST, Weidman WH, Michels VV, Reed TJ, Ormson CL, Fuller T, and Sing CF (1989) Distribution of sodium-lithium countertransport and blood pressure in caucasians five to eighty-nine years of age. Hyper- 
tension 13:378-391

Ward RH (1972) The genetic structure of a tribal population, the Yanomama Indians. V. Comparison of a series of genetic networks. Ann. Hum. Genet. (Lond.) $36: 21-43$.

Ward RH (1983) Genetic and sociocultural components of high blood pressure. Am. J. Phys. Anthropol. 62:91-105.

Ward RH (1985) Isolates in transition: A research paradigm for genetic epidemiology. In Chakraborty R, and Szathmary EJE (eds.): Diseases of Complex Etiology in Small Populations: Ethnic Differences and Research Approaches. New York: Alan R. Liss, Inc., pp. $147-177$
Ward RH, Chin PG, and Prior IAM (1979) Genetic epidemiology of blood pressure in a migrating isolate: Prospectus. In Sing CF, and Skolnick MH (eds.): Genetic Analysis of Common Diseases: Applications to Predictive Factors in Coronary Disease. New York: Alan R. Liss, Inc., pp. 675-709.

Ward RH, and Neel $J$ (1976) The genetic structure of a tribal population, the Yanomama Indians. XIV. Clines and their interpretations. Genetics 82:103-121.

Whyte HM (1958) Body fat and blood pressure of natives in New Guinea: Reflections on essential hypertension. Aust. Ann. Med. 7:36-46. 